\title{
"I Really Want to Save Our Language": Facing the Challenge of Revitalising and Maintaining Southern Sami Language through Schooling
}

\author{
Kitt Margaret Lyngsnes ${ }^{1}$ \\ ${ }^{1}$ Faculty of Teacher Education, Nord-Trondelag University College, Levanger, Norway \\ Correspondence: Kitt Margaret Lyngsnes, Nord-Trondelag University College, 7600 Levanger, Norway. Tel: \\ 47-7402-2707. E-mail: kitt.lyngsnes@hint.no
}

Received: January 25, 2013 Accepted: January 31, 2013 Online Published: February 25, 2013

doi:10.5539/ies.v6n3p228

URL: http://dx.doi.org/10.5539/ies.v6n3p228

\begin{abstract}
This article is based on a study of Southern Sami language learning in Norway. There are around 600-1000 Southern Sami living widely dispersed over a large territorial area in Norway. As an indigenous people, they have a right to instruction in their own language. The Southern Sami language however is in danger of extinction. The purpose of this article is to explore how Southern Sami language learning is organised and implemented in school and, whether this training contributes to revitalising and maintaining the language. Data is collected in the contexts of the main Southern Sami language learning schools through qualitative interviews with pupils, teachers, headmasters, and parents. A sociocultural theoretical framework is used to analyse the data. The findings show that Southern Sami language learning in school offers very limited access to a Southern Sami language community due to the small number of pupils and teachers, lack of learning materials and most importantly the overall lack of language arenas for Southern Sami language. Another finding was that enthusiasm and motivation for learning and saving the language was very extensive.
\end{abstract}

Keywords: Sami, Southern Sami, language learning, indigenous people

\section{Introduction}

\subsection{Situating the Sami}

The Sami people have lived for centuries in the northern areas of Norway, Sweden and Finland and the Russian Kola Peninsula. Although the Sami are divided by national boundaries and by significant differences in Sami languages and dialects, they consider themselves as one people, united by cultural and linguistic bonds and a common identity. The Sami have the oldest languages and cultures of these countries, pre-dating the present-day states by a long time (Anaya, 2011, p. 4). Based on their history, livelihoods, worldview, and language the Sami have a status as an indigenous people. In Norway the Sami have the right to special protection and the right to exercise a high degree of influence over their living conditions in accordance with international conventions regarding indigenous people, ratified by the Norwegian government. The principal foundation for Sami policy in Norway is an amendment in 1988 to the Norwegian Constitution, the "Sami Act". Here authorities are explicitly called upon to protect the Sami and their culture, and it is stated that it is the responsibility of the authorities of Norway to create conditions enabling the Sami people to maintain and develop its language, culture and way of life.

How to define Sami are a complicated matter and an ongoing discussion (Pettersen, 2007; Åhren, 2008). Traditionally the Sami have been employed with reindeer husbandry or other primary industry. Today however the Sami is a more heterogeneous group being employed in lots of different trades and professions. Yet "Sami-ness" can be understood according to different aspects relating to family heritage, language use and individually determined perception of belonging to the ethnic Sami community (Hellstén, 1998, p. 121). The Sami culture is not one consistent unity, but comprises several cultures and languages. A number of individuals and families with a Sami heritage have chosen not to stand out as Sami or to take up Sami language and culture. Due to the challenge concerning defining who are Sami, there are different estimates of the number of Sami. Nordic Sami Institute (2005) refers to a common estimate of about 50-80 000 Sami in the four countries. The majority of them, around 40-65 000 live in Norway. 
Sami is a Uralic language and is very different from the Indo-European languages, e.g. Norwegian, which surround the Sami people. Within an extensive geographical area, such as the Sami inhabit, there will be differences in language and dialects. These are so fundamental that Sami speakers from peripheral areas cannot understand each other. Consequently, different Sami languages have evolved, and the language boundaries do not follow national boundaries (Todal, 1998, p. 356). In Norway the Sami minority has three different official language forms; Northern Sami, Lule Sami and Southern Sami. These are significantly different, and all three of them have their own official written form. Estimating the number of different Sami languages users is challenging. Roughly calculated the number of Northern Sami speakers in Norway is 10 000-15 000, Lule Sami speakers around 500, and Southern Sami speakers around 300-500 (Magga, 2002; Lewis, 2009).

\subsection{From Norwegianisation to Sami Curriculum}

For centuries, different actions for assimilation were implemented in order to make the "wild and primitive Sami" as Norwegian as possible in language, culture and their overall view of themselves (Todal, 1998, p. 357). During the 1700s and 1800s, various bishops and missionaries initiated and established a Christian mission towards the Sami. The "Norwegianisation"-policy was developed by the Norwegian government from the mid-1800s. "The policy of Norwegianisation was introduced in the field of culture with school as the battlefield and teachers as frontline soldiers" (Niemi, 1997, p. 268). Consequently, the war of extermination against Sami languages was given priority. Boarding schools for Sami children where no Sami language was allowed and "unfavourable" influence from their family was avoided, were a vital means in the process (Jensen, 2005; Hoëm, 2007; Solstad et al., 2009). Until 1959, Sami children were strictly forbidden to speak Sami at school (Bjørklund, 2000, p.9).

The assimilation policy lasted until the 1960s. Because of this oppression of Sami language and ways of life, during the years, many individuals and families have hidden their Sami identity. According to Minde (2005), this attitude to their native language was quite common among the Sami, especially among those who wished to rise in the Norwegian society. It was a widely held opinion that tending the Sami language was a futile business. Being taken for a Sami in public was a personal defeat (Minde, ibid). Today however Sami self-opinion is continually changing through democracy and the development of autonomy for indigenous peoples and minorities (Hirvonen \& Keskitalo, 2004, p. 205). The changes in policy made by the Norwegian government the last decades have been complemented by changes in Sami attitudes towards their own language and culture (Özerk, 2009, p. 139).

Today the basis for instruction in Sami languages in Norway is rooted in "The Sami Act" in the Constitution, the Law of Education from 1998 and The National curriculum for the Knowledge Promotion 2006. These documents ensure that pupils in primary and secondary education and training in Sami districts have the right to receive their education in Sami. It also gives Sami pupils an individual right to learn the Sami language wherever they live. The National curriculum contains a particular Sami curriculum (Utdanningsdirektoratet, 2006). Pupils learning Sami can choose between Sami as their first or second language. Sami as a first language is for pupils who master one of the Sami languages, while Sami as a second language is for pupils who have little or no competence in Sami.

\subsection{Problem of Research: The Southern Sami-A Minority within the Minority}

The Sami struggle to maintain and develop their languages and culture. Revitalising a language means "a conscious effort to curtail the assimilative development of a language which has been steadily decreasing in use and to give it a new life and vigour" (Huss, 1999, p. 24). For the smallest of the Sami languages the question is whether they will be able to survive.

This article focuses on a small language and a small group of Sami people in Norway, the Southern Sami. The Southern Sami population of 600-1000 individuals is small and widely dispersed over a large territorial area. The distance from the northern to the southern settlements is around 750 kilometres. The Southern Sami are not a majority in any municipality or village. Nor is there any local society where Southern Sami language is the common language of communication. The Southern Sami language is on UNESCO's "red list" of languages in danger of extinction due to the limited number of people mastering it. Because of the widespread population and very few Southern Sami residents compared to the majority population, revitalising and saving the Southern Sami language is a major challenge.

About half of the Southern Sami population master the language, and approximately 100 pupils receive instruction in Southern Sami in the Norwegian ten-year compulsory (primary and secondary) schools annually. This number has been relatively stable for more than ten years. Of these 100 pupils around 15-20 have Southern Sami as their first language, and attend one of the two Sami boarding schools in the Southern Sami area. The rest 
have Southern Sami as their second language and receive language instruction at a Sami school or in their home school with a Sami teacher, or as distance education combined with gatherings at Sami schools. The volume of instruction is 3-4 lessons a week depending on the class level. Altogether, these pupils are to be found at 35 schools in 6 counties.

Bearing in mind the low number of Southern Sami speakers and the widespread population, this article will place emphasis on educational challenges concerning teaching and learning Southern Sami language in Norwegian schools, and furthermore, how these activities relate to saving the language. Focus will be on the following questions: How is Southern Sami language learning organised and implemented, and How does Southern Sami language learning in school contribute to vitalising and maintaining the language?

\subsection{Relevant Research}

The UN's special rapporteur on indigenous rights points out that among the countries with a Sami population the Norwegian authorities have taken most responsibility to ensure the rights of the Sami people and to provide Sami children and young people with culturally appropriate education (Anaya, 2011). "Norway has the best premises to carry out the Sami education as secured by law and because of the Sami curriculum and the special Sami school system" (Keskitalo, Määttä, \& Uusiautti, 2012, p. 336).

An extended study of Sami education based on the Norwegian national curriculum from 1997 showed that outside the Sami districts schools, only the subject Sami language was taught in Sami, and that the subjects and activities were to a very limited extent connected to Sami culture and context (Hirvonen \& Keskitalo, 2004). The Norwegianisation led to a disparagement of Sami culture, and this gives reasons to believe that there are few traces of Sami culture to be found in the Norwegian textbooks (Fyhn, 2009). Often textbooks are Norwegian books translated into a Sami language.

A recent extended evaluation of Sami education in Norwegian schools (Solstad et.al., 2009; Solstad, et.al., 2010; Solstad, Nygaard, \& Solstad, 2012) also found that most Sami education, even in Sami districts, were dominated by Norwegian language. Furthermore, there was a lack of qualified Sami teachers and Sami learning materials. In most cases the training took place in Sami as a second language, and was provided by a combination of distance education and joint gatherings. Pupils living in Sami districts (mostly Northern Sami) had stronger language support in their community, and thus better conditions to learn the language. The Southern Sami children had far less language support in their schools and local environment.

$15 \%$ of the parents in Sami areas stated that they did not find that it is vital for their children to learn Sami (Solstad, Nygaard \& Solstad, 2012). The same number found it quite important, but not to such an extent, that they had taken initiative to get language instruction established for their children. The most important reason that Sami children did not learn Sami was, however, lack of relevant educational resources. Sixty percent of the parents in the study pointed to this kind of reason. The most significant motive was that there were too few or no qualified teachers. Another substantial problem was that according to the National curriculum the time for instruction in Sami language is to be taken partly from time for instruction in Norwegian and partly as supplemental lessons. During the seven years of primary school, children learning Sami language as their second language receive 190 lessons more than children learning only Norwegian do. School leaders reported extensive struggles in getting qualified teachers and in making a timetable that was acceptable for pupils, teachers, and parents. One third of the parents found that the organisation and structure of Sami education was inadequate. They reported on lack of information, lack of teachers and often a quite disorganised school day for their children where the Sami instruction was not integrated in the overall activity in the school (Solstad, Nygaard \& Solstad, 2012).

In a study of the Sami language situation Solstad, Balto, Nygaard, Josefsen and Solstad (2012) found that Sami language more than anything, is a medium for communication in the private sphere. Opportunities for using Sami are not always enough for actually practising it. Only one in every five Southern Sami, and one in every three Lule Sami reported using the language in situations where it could be used. Even within the Northern Sami municipalities, only two of three claimed to choose the Sami language most often when possible. A main reason for avoiding using Sami language was a feeling of insufficient skills and consequently a fear of making mistakes. Many pointed to being particularly reluctant to apply Sami when talking to someone regarded as especially good Sami speakers (Solstad, et.al, ibid). Language proficiency is particularly difficult for the Southern Sami people. Most of them live in communities, which are predominantly Norwegian speaking, and with no or very little Sami language support. When it came to age, Solstad, Balto, Nygaard, Josefsen and Solstad (2012, p.17) found that more younger than older people possess skills in reading and writing the Southern Sami language. The generation of those over 50 tends to master the language mainly orally. The improved skills in reading and 
writing among the younger people correspond to the period where there has been a marked up-scaling of Sami instruction across school levels. All the same, essentially all Southern Sami children have a command of the Norwegian language, and quite many of them do not receive Sami instruction.

Many studies concerning bilingual education and the school's role in revitalising and maintaining a language conclude that it is necessary that both languages have to be used as media of instruction in subjects other than the language themselves (Skutnabb-Kangas, 2000; Baker, 2011). Todal (2011) concludes that the educational models for learning Sami as a second language do not develop bilingualism for Norwegian speaking Sami children.

\subsection{Theoretical Framework}

The last decades there has been a sociocultural shift regarding learning from seeing learners as individual knowledge producers to seeing them as members of social and historical communities. A sociocultural perspective directs research toward examining the conditions for learning, and the issues of access to learners for appropriation of practices, in any particular community. Vygotsky $(1978 ; 2000)$ pointed to language as the most vital tool in learning processes. This theoretical framework establishes that language learning is context-embedded, and one needs to integrate the learner and the language learning context.

Lave and Wenger (1991) argue that learning is an integral and inseparable part of social practice as newcomers participate with "old-timers" in performance of community practices. They are centrally concerned with the relationship between learning and the social situation in which it occurs, a relationship they refer to as situated learning. Through a process of legitimate peripheral participation newcomers interact with old-timers in a given community setting, become increasingly experienced in the practices that characterize that community, and gradually move towards fuller participation in the community. The particular social arrangements in any community may constrain or facilitate movement towards fuller participation:

The key to legitimate peripheral participation is access by newcomers to the community of practice and all that membership entails. But though this is essential to the reproduction of the community, it is always problematic at the same time. To become a full member of a community of practice requires access to a wide range of ongoing activity, old-timers, and other members of the community; and to information, resources and opportunities for participation (Lave \& Wenger, 1991, p. 100).

Lave and Wenger (ibid) call attention to the importance of not sequestering newcomers away from participation in community activities if they are to learn. They note that, ideally, learners must see, or be in the presence of mature practice. Situated learning theory (Lave \& Wenger, 1991; Wenger, 1998) offers interesting perspectives for research on language and education. Language learning is a social practice that takes place I,n as well as through, social interaction and participation in communities. A situated perspective on individuals' participation and non-participation in a learning context might enhance the understanding of language teaching and learning (Norton, 2001). With this point of departure, contextual conditions, as well as possibilities and barriers for participation, become important issues in understanding language learning (Lund, 2006, p. 57).

Accordingly, Baker's (2011) typology for bilingual education might contribute to gaining insight into learning environments for the language learner. This typology distinguishes between strong and weak forms of bilingual education according to the language background of the pupil, the language of the classroom, and the linguistic, societal, and educational aims. According to Baker, the aim of the language learning and the language used for communication in the classroom play the decisive role characterising education as weak or strong. Baker establishes the education as strong if the aim is bilingualism and if the two languages are used actively and generally in school as a means of communication in other subjects than the languages themselves. A weak form of education is characterised by limited use of the minority language in school. The language of the classroom in weak forms will tend to be the majority language. If the minority language is spoken and written only in the minority language lessons and the aim is limited competence in the language, it will be a weak form of education. Baker claims that strong models are necessary if pupils are to be active users of the minority language.

In this article Lave and Wenger's work about situated learning and Baker's notion of strong and weak forms of bilingual education will make up a theoretical lens to enhance the understanding of Southern Sami language learning in a context of revitalising and maintaining the language.

\section{Method}

To provide insights into Southern Sami language learning it was vital to explore both the organisation of and the context for the education, and the experiences of the different participants. The Southern Sami people live widespread, and it was important for the study's purpose to include participants representing both typicality and variation (Patton, 1990). The selection criteria were thus "information-oriented". That entails that the purpose is 
to maximize the utility of information by selecting informants based on expectations about their information content (Flyvbjerg, 2004, p. 426). Consequently, pupils, parents, teachers, and headmasters were included, and data was collected at different schools in different contexts.

In selecting participants and conducting the study, a number of ethical considerations were attended to. Many studies have noted the difficulties and challenges of recruitment of minority ethnic groups for participation in research (Knight et al, 2004; Yancey et al, 2006). The Sami is an indigenous people with a history of Norwegianisation that might lead to a kind of reluctance towards non-Sami researchers who are not part of the Sami history and culture. In order not to impose research on the Southern Sami people, selecting participants from the educational context was done by "snowball sampling". Snowball sampling is a technique for gathering research subjects through the identification of an initial subject who is used to provide the names of others. These persons may themselves open possibilities for an expanding web of contact and inquiry (Atkinson \& Flint, 2004). At first the headmasters were contacted directly, and requests for interview were made. Via them we got the name and phone numbers of teachers and parents. These were then asked to be interviewed. The parents in turn, gave permission for their children to participate in group interviews.

The fieldwork was carried out at four different schools. Among them were a Southern Sami boarding school and different other schools where pupils were learning the language. Interviews were conducted with: three headmasters, four teachers, eighteen pupils, and four parents. The sample thus covered the main learning contexts and relevant participants in Southern Sami education.

The participants were all interviewed once, and the interviews were semi structured (Kvale, 1996). In this type of interview the order of the themes and questions can be changed depending on the direction of the interview thus providing opportunities for both the interviewer and interviewee to discuss certain topics in more detail. The researcher might explore, probe, and ask questions spontaneously that will elucidate and illuminate the particular subject area and establish a conversational style but with the focus on the particular subject that has been predetermined (Patton, 2002, p. 343). The headmasters and the Sami teachers were interviewed individually. The pupils were interviewed in groups from two to four, and the parents were interviewed individually by telephone. An interview guide for each group of participants was prepared. The themes differed slightly in the guides, but central themes were about teacher competence, pupils' and parents' language proficiency, learning materials, ways of teaching, tasks and homework, timetables, collaboration between teachers, between school and parents, and involvement with organisations and activities outside school.

An important ethical issue to be considered in this project was that the Southern Sami population is so small that total anonymity is impossible. This was pointed out from a few of the participants as well, and to maintain anonymity to the greatest possible extent no names or other characteristics will be referred to, and all the participants are called "he" regardless of their sex. It might be difficult to anonymise at the school level. At the individual level, however, we will, as far as possible, avoid giving information about who is responsible for particular statements.

The interviews were audio taped. Then the entire interviews were transcribed by the researcher. Productions of transcripts are "research activities" because they involve close, repeated listening to recordings that often reveal previously unnoticed features of the conversation (Atkinson \& Heritage, 1984). Each interview was coded and analysed both within and across the participants stories to procedures outlined in the constant comparative method (Corbin \& Strauss, 2008). The analysis moved back and forth between transcribed texts and theoretical assumptions, and this interplay between theory and data gave opportunities to ask questions, make comparisons between the unorganised data, and search for appropriate categories. Throughout the analysis, three analytical categories emerged in the data material. The first category is named language learning resources and refers to existing learning material, like books and digital media, and teacher competence in Southern Sami language. The second category is named language learning activities. In addition to the activities carried out during the Southern Sami lessons, this category also includes the timetables and the conditions for activities they gave. The third category is language learning arenas and refers to the different arenas and contexts where the children used or might use the Southern Sami language. Such analytical categories are related to each other and are not as such mutually independent, but useful in enhancing the insight in Southern Sami language learning in school.

To assure the study's credibility the interviews were transcribed verbatim, including both the interviewer's and the participant's statements (McLellan, Macqueen \& Neidig, 2003). Member checking is a procedure designed to enhance study credibility and participant involvement (Creswell \& Miller, 2000), and the participants were offered the opportunity to read the transcripts. None of them were interested in doing so. To gain more than one viewpoint on the data, they were also discussed in a group of researchers all working with Sami studies. 


\section{Results}

In this section, the different school contexts where Southern Sami language learning takes place are described.

\subsection{The Sami Primary School}

The Sami primary school, where the pupils are aged 6-13, is placed in one of the municipalities with a certain concentration of Southern Sami. The school offers education for Southern Sami children from nearby areas and for children from other parts of the scattered Southern Sami settlements. For those who live so far away that they cannot stay at home outside school hours, the school functions as a boarding school with a nearby hall of residence.

At the time of the data collection in this project there were eleven pupils dispersed on the seven grades. Four of these were living at the hall of residence and went home about every third weekend. The pupils are flexibly grouped, and most of them have Sami as their second language. When entering the school Sami signs and posters are seen around. However, the Norwegian language dominates the Sami school in many ways. The headmaster of the school is not a Sami and he does not master the Southern Sami language. He is able to make polite remarks and a few set phrases in the language. The pupils that were interviewed master the language to a certain degree. They all confirm however that even if Southern Sami sometimes is used, they mostly speak Norwegian both at home and at school. The pupils speak Sami in the Sami lessons, and in a few instances, in the other subjects if the teacher masters the language. All informants consider that Norwegian is the common language, and that the kids at the Sami school largely use Norwegian to communicate with each other both about school subjects and when they play.

There are altogether seven teachers at the Sami school, most of them working part-time. Four of them have formal education in the Southern Sami language. The teachers point to problems regarding supply of qualified language teachers and to lack of teaching materials:

To teach history or religion in Southern Sami, you have to translate texts yourself. Sometimes we try to compose texts. A Sami teacher should be a good writer, a good illustrator and know a lot about lay-out. Actually, one should have been a magician (laughter).

Regarding the future for the language, one of the teachers expresses an optimistic view. He has been a teacher of Sami for about 20 years and assesses the children's competence in Southern Sami as better today than a few years ago. He also points to the fact that more parents try to learn Sami themselves to support their children. The pupils also show a great interest for Southern Sami. They express a wish for more Sami lessons to learn more about Sami and to become better at speaking and writing.

The parents in our study who have chosen to send their children to the Sami school underline that they have been in a great dilemma. They believe it so important, however, to bear up the Southern Sami heritage and they find the distance education so poor, that they have made this decision.

\subsection{Secondary School and Upper Secondary School with Sami Teacher at the Schools}

Close to the Sami school there is a secondary school. At this school, with its three levels, there are about 100 pupils altogether. Eight of them are studying Southern Sami; seven as their second language and one as his first language. The first language pupil receives instruction alone with the teacher. The others are in groups of two and three. Most of the pupils here had attended the Sami school earlier. A few live at the residence hall. One of them has been living away from home since he was ten years old to get "the best Southern Sami education" as he expresses it. One of the others had, together with his parents, made the decision to go to this school and live away from home the previous year. They found the distance education he received at his home school too unsatisfactory.

Since this is a school where most of the pupils do not read Sami, there are quite a few challenges regarding the timetable. The headmaster describes the efforts that are made to rotate the Sami lessons at different times so that no subject is affected too much. Thus the pupils read Sami in about half of the Norwegian language lessons and sometimes in lesson of religion, science, physical education or others. This situation is unsatisfactory for the pupils when there are exiting or interesting things going on in the other subjects.

The language teacher comes over from the Sami school to teach the eight students in their different groups. The teacher expresses that, for him, a primary goal in teaching is to encourage these pupils in their mainly Norwegian context, to use the language both at school and at home. He too points, however, to challenges regarding learning materials and methods:

The goals of the National curriculum do not match reality. Examples are that according to the curriculum 
the pupils are to use the internet to find information, they are supposed to be reading literature, searching newspapers and watching TV-programs to learn about different topics. In reality there is no information in Southern Sami to be found on the web, there are no Southern Sami newspapers or TV-programs, and the few existing books we have already read to pieces.

In the upper secondary school in the study there are six students receiving instruction in Southern Sami as their second language. These belong to different programmes, and problems regarding the organisation and their timetables are considerable. In many programmes, there is no possibility to have Sami instead of other subjects. One of the students says: "I have eleven subjects already, and Sami comes on the top. But that is in fact no problem because I am so eager to learn Southern Sami. I really want to save our language!" None of the students speak Southern Sami fluently, but they understand the language when it is spoken by others and have a strong wish to learn more. The students' powerful motivations for learning Southern Sami are confirmed by the teacher. He tells that one year it was not at all possible to find place for the all the Sami teaching in the timetable. Lessons were held between six and eight o'clock in Friday afternoon for two students who were satisfied with this solution.

Like the other Southern Sami language teachers in this study, this teacher also considers the situation regarding teaching materials as difficult. According to him, textbooks in Southern Sami for upper secondary school have never been written. The headmaster points out this fact as well: "There is money on our budget, but there are no Southern Sami teaching materials to buy!" The consequence of this situation is that writing and photocopying texts is a central part of the teacher's preparations for the lessons. The students find the learning activities quite predictable and monotonous most often consisting of reading the texts, retelling them, and writing a summary of them. Translating texts between Norwegian and Southern Sami is another usual activity.

\subsection{Distance Education}

The most common model for Southern Sami language learning is distance education. Competent language teachers are rare around the vast area with the sparse Southern Sami settlements. The two Southern Sami schools and an upper secondary school with a Southern Sami resource centre are responsible for distance education for pupils attending their home schools. Distance education is based on the three elements -- digital learning, visiting teacher, and gatherings. There are different combinations and models of these. For example, the teacher at the upper secondary school in our study gives instruction via internet to two students at a school 80 kilometres from his. He also goes to this school one day a month to teach them "live". Another example is that 13 pupils in 11 different schools in four different counties receive distance education from the school with the Southern Sami resource centre. One of the teachers who teaches Southern Sami via internet calls attention to the many challenges in this kind of instruction:

Although we have few students, it is very resource demanding. We are related to so many schools in so many counties. These have, for example, three different dates for the winter holiday. Furthermore, the schools starts at slightly different times in the morning, they have some differences in organising their schedule, and the pupils leave different subjects in their class to receive Southern Sami instruction at different times. Thus, there are microscopically chances to coordinate the instruction, and we have quite a puzzle to put together!

In distance education like this, the pupils do not "meet" each other. They are left alone with their computer at their school, communicating merely with the teacher at the resource school. Webcam, Skype and video conferencing equipment are the usual technical tools. It appears, however, that there are considerable variations regarding technical equipment at the home schools. One of the pupils tells us that he was so tired of the school's poor computers that did not work, that he brought his own computer to receive instruction via the web. The ways the home schools follow up and pay attention to the learning processes of the pupils receiving distance education differ considerably as well. One of the teachers describes schools where the Sami pupil has an assistant to help in the teaching situation and teachers continuously observing the Sami pupil and his distance education. At other schools children are left completely to themselves. A parent describes the setting for distance education for his seven year child who is the only Southern Sami pupil at his home school:

The Sami lesson started halfway into the lunch break. The school therefore equipped him with a timer so he could keep track of the time himself. When the timer beeped - if he remembered bringing it with him in the play - he entered his little "closet", received his instruction if he could make the technical equipment work, and came out to the class after the lesson. The school and the classmates did not know what he had been doing. He sort of went into his own little world.

These parents later chose to send their child to a Sami boarding school. 
Supplementing the digital instruction the Sami schools also organise language gatherings for the pupils from these widespread areas. These gatherings vary in length and frequency, from three days twice a year at one Sami school to six whole weeks a year at another school. The number of pupils attending each of these gatherings was this year between nine and twelve. The gatherings also vary in content and activities. There is usually a main theme for the gathering, like Sami handicraft (Duedtie), Indigenous people around the world or Sami folk tales and legends. One of the teachers describes that the purpose of the gatherings is to place the Sami language in a cultural context, to develop a network and a social community for the Sami pupils, to strengthen their Sami identity, and to increase their motivation for further education in Sami. Here the pupils meet other Southern Sami children and young people, and they meet the language and the Sami culture. Some of the pupils do not receive instruction in Southern Sami language at their home school, because they find it too stressful to take on an extra language and to lose parts of other subjects. They emphasise however how important it is for them to meet other Sami young people, Sami language and culture and develop and strengthen their Southern Sami identity: "You get experiences that stick in your mind. It is not just knowledge; it is memories and friends as well. You bring it with you in your life and in a way, you feel even more Sami. The Southern Sami identity seems to be important for the young people and this is underlined in statements such as: "Many people think it's cool to be a Sami", and "I'm actually quite proud of being a Sami".

In our study all the teachers are highly committed and work hard to revitalise Southern Sami language, culture and identity. Some of them are however beginning to feel a little worn out:

Most of us who work with Southern Sami are doing a lot of things, and many of us educate ourselves along the way, because we lack the basic language education. But I and others with me, have soon reached a saturation point. I'm a little afraid of what will happen. We would really want to go on, but I'm afraid we burn out, because we are so few. [...] There's a tremendous lot of work to be done. We have lost the language for two generations. Now we try to get it back again, and it requires resources and it requires work!

\section{Discussion}

In the first part of the discussion section the three analytical categories that are empirically developed and sociocultural theory are used to analyse and generate insights into Southern Sami language learning.

\subsection{Southern Sami Language Learning: Resources, Activities and Arenas}

In conceptualising Southern Sami language learning a sociocultural frame of understanding learning, implying that the learner cannot be separated from the learning context, seems particularly apt. Learning takes place in participation and joint activity with others using cultural tools (Vygotsky, 1978). In drawing on situated learning concepts to enhance the understanding of Southern Sami language learning it is, therefore, important to bear in mind that learning is an integral and inseparable part of social practice as newcomers participate with "old-timers" in a community of practice (Lave \& Wenger, 1991). Those mastering the Southern Sami language might be considered to constitute a community of practice. This is a community in a literal manner of speaking and not a permanently or geographically set community. The members do not necessarily know each other, but are bound together by their Southern Sami language and culture. The Southern Sami language community represented by "old-timers", that is individuals mastering the language, and by cultural tools like books can be found in families, language classrooms, schools, media, neighbourhoods and so on.

In our study, both children, young people and parents, on their children's behalf, expressed strong desires to become members of this Southern Sami community of language. To become a competent and full member of a community however, access to participation in different ways in the community and its cultural tools is vital. Our analysis suggests that the three empirical categories language learning resources, language learning activities and language learning arenas represent opportunities or lack of opportunities for access to the language and the participation in the community of Southern Sami language users. Learning is closely connected to the access given. Our study indicates that such access was unequal for the pupils in the different educational contexts and generally limited for the Southern Sami learners.

An important factor to open up a language is the resources and tools available. Resources in terms of books, web sites, TV-programs etc in Southern Sami exist to a very modest extent. Limited access to the language via these traditional learning materials was therefore a common problem in all Southern Sami language learning. A common problem was also the lack of teachers with education in Southern Sami language. Moving towards membership in a language community implies activities where the language is learned in different ways. Because of the lack of learning materials and the lack of Southern Sami language teachers, the access to participation in a variety of activities was limited. Activities often circled around the teachers' "home-made 
texts". For the majority of the children who had no Southern Sami teacher at their school, and therefore received distance education, the predictability and monotony of activities were dominant. They had to sit all by themselves in a room with a Southern Sami language teacher coming up on their computer screen trying to communicate and working with texts.

To learn the Southern Sami language it is vital to get access to arenas where the language is used. When pupils enter the Southern Sami classroom they meet a teacher speaking the target language and thus represents a more experienced member of the Southern Sami language community. In our study, we saw that most of the Southern Sami language learners did not belong to a class. They learned the language alone or in a group of 2-4 participants. Thus, the chance to do exercises and practice the language together with others was very restricted. Apart from the pupils at the Sami school, the only member of the language community most pupils met was the teacher. Access to language arenas was thus extremely limited in school. By and large the distance education pupil like the seven year old with the timer, described above, was shut out of the language community. Since there is no village or district where Southern Sami dominates over Norwegian as the spoken language in daily use, and since there are no papers or TV-programs in Southern Sami, the only arenas outside the instruction at school where most pupils met the language, was if their family used it or if they attended the language gatherings. At the gatherings, many young people that did not study Southern Sami at their home school participated. For them the gatherings functioned more like a social and cultural and not a language learning arena. This was, for them, an important kind of participation - moving from a peripheral to a more central position - in the Southern Sami community, "feeling even more Sami" as one of them put it. As an arena for language learning, on the other hand, the gatherings were of limited value even for those who came to develop their language abilities, because the activities had to be adapted to them with no knowledge of Southern Sami.

As seen in our study many Southern Sami parents chose to send their children to the Sami school to secure the best possible access to the Southern Sami language and culture. The Sami school had some advantages as an arena for Southern Sami language learning. Because all the children are learning Southern Sami as their first or second language at the Sami school, there are no problems regarding timetables or losing instruction in other subjects, and more varied activities could find a place. The existing selection of Southern Sami learning materials was available there, most of the teachers mastered Southern Sami, and even those working at the residence hall were Southern Sami speakers. Thus, one could suppose that this was an excellent language arena. Nevertheless, even here the kids largely used Norwegian as the language for both communication and play.

Children, young people and parents in our study showed great enthusiasm and motivation for learning and revitalising Southern Sami. Some of the parents were even trying to develop a language arena at home by studying Southern Sami themselves in their spare time. However, of course this was often problematic because there are so few qualified teachers to give this kind of courses.

\subsection{Is There A Future for the Southern Sami Language?}

In Norway Sami children have an individual right to be educated in their language irrespective of the geographical area they live in. Taking into account the small number of Southern Sami speakers, and the fact that the language is on UNESCO's red list, it is relevant to raise the question as to whether the present organisation and implementation of Southern Sami language learning contribute to revitalising and maintaining the language. One might even go further and ask if it is at all possible to revitalise and maintain the Southern Sami language with the help of the school system.

Norwegian is the main language of teaching and communication for most of the Southern Sami children, except for the Sami schools where there are considerable elements of Southern Sami language. Most of the pupils study Southern Sami as a second language, and since the majority does not attend a Sami school, they are pulled out of their "Norwegian" classrooms to get distance education or instruction in small groups. The number of lessons a week is 3-4. As our study demonstrates, this learning context gives the Southern Sami language learners very limited access to language arenas where Southern Sami is used. Applying Baker's (2011) notion of strong and weak forms of language education on this situation, one can conclude that Southern Sami language learning and instruction today is a weak model. Characteristic for a weak model is that the target language is used only in the language lessons, like Southern Sami is outside the Sami schools, and that the aim is limited competence, as it is in Southern Sami as a second language. Skutnabb-Kangas (2000) has divided Baker's weak form of bilingual education further into a weak form and a non-form. Most of the distance education models in Southern Sami might be considered to be close to a non-form. A non-form includes mainstream monolingual programs with the target language taught as a subject in seclusion, and according to Skutnabb-Kangas it leads to monolingualism.

Hinton (2001) points to the immense challenge it is to revitalise a language through a language-as-a-subject 
program, where there will not be enough time or possibilities to put the language to practical use. On the other hand, such a program can stimulate children and young people to overcome shyness and shame and create an eagerness and motivation to learn their language. This eagerness is clearly pronounced by the informants in all ages and in all the school contexts in our study! They want to revitalise and save the language. This enthusiasm and all the efforts made by, for instance, young people attending Sami lessons on top of their other subjects, parents learning the language to support their children, parents sending their children to a Sami school, and teachers educating themselves and producing learning materials, are extensive contributions to revitalising and maintaining Southern Sami. Fishman (1991) who has studied languages revitalising processes underlines the importance of using the language in homes and at community social occasions. The uttermost important factor in ensuring the survival of a language according to Fishman is that parents speak the language with their children. The old saying "use it or lose it" goes for the indigenous language Southern Sami as well as many other things in life.

\section{Acknowledgements}

This article draws upon data collected as part of an extended study Evaluating the Knowledge Promotion Reform - 2006 Sami. The project was assigned and funded by the Norwegian Directorate for Education and Training, and the project manager was Professor Karl Jan Solstad, Nordland Research Institute.

\section{References}

Åhren, C. (2008). Är jag en riktig same? En etnologisk studie av unga samers identitetsarbeid. Umeå: Umeå universitet.

Anaya, J. (2011). The situation of the Sami people in the Sápmi region of Norway,Sweden and Finland. Report of the Special Rapporteur on the rights of indigenous peoples. UN. Retrieved October 9, 2012, from http://unsr.jamesanaya.org/country-reports/the-situation-of-the-sami-people-in-the-sapmi-region-of-norway -sweden-and-finland-2011

Atkinson, J. M., \& Heritage, J. (1984). Transcript notation. In J. M. Atkinson, \& J. Heritage (Eds.), Structures of social action (pp. ix-xvi). Cambridge: Cambridge University Press.

Atkinson, R., \& Flint, J. (2004). Snowball sampling. In M. Lewis-Beck, A. Bryman, \& T. Liao (Eds.), Encyclopedia of social science research methods (pp. 1044-1045). Thousand Oaks, CA: Sage Publications. http://dx.doi.org/10.4135/9781412950589

Baker, C. (2011). Foundations of bilingual education and bilingualism (5th ed.). Clevedon: Multilingual Matters.

Bjørklund, I. (2000). Sápmi - en nasjon blir til. Tromsø: Tromsø museum, Universitetet i Tromsø.

Corbin, J., \& Strauss, A. (2008). Basics of qualitative research: Techniques and procedures for developing grounded theory (3th ed.). Los Angeles, CA: Sage Publications.

Creswell, J. W., \& Miller, D. L. (2000). Determining validity in qualitative inquiry. Theory into Practice, 39(3), 24-130. http://dx.doi.org/10.1207/s15430421tip3903_2

Fishman, J. (1991). Reversing language shift. Theoretical and empirical foundations of assistance to threatened languages. Clevedon: Multilingual Matters.

Flyvbjerg, B. (2004). Five misunderstandings about case-study research. In C. Seale, G. Gobo, J. F. Gubrium, \& D. Silverman (Eds.), Qualitative research practice (pp. 420-435). London: Sage Publications.

Fyhn, A. B. (2009). Sami culture and algebra in the curriculum. Paper presented at CERME $6^{\text {th }}$ Conference of European Research in Mathematics Education (Jan. $28^{\text {th }}-$ Feb. 1th), Lyon, France.

Hellstén, M. (1998). The Sami identity: A souvenir or something living? Language and Education, 12(2), 19-136. http://dx.doi.org/10.1080/09500789808666743

Hinton, L. (2001). Language revitalization: an overview. In L. Hinton, \& K. Hale (Eds.), The green book of language revitalization in practice (pp. 3-18). San Diego: Academic Press.

Hirvonen, V., \& Keskitalo, J. H. (2004). Samisk skole - en ufullendt symfoni? In K. J. Solstad, \& T. O. Engen (Eds.), En likeverdig skole for alle? Om enhet og mangfold $i$ grunnskolen (pp. 200-219). Oslo: Universitetsforlaget.

Hoëm, A. (2007). Fra noaidiens verden til forskerens. Misjon, kunnskap og moderninsering $i$ sameland 1715-2007. Oslo: Novus forlag. 
Huss, L. (1999). Reversing language shift in the Far North, linguistic revitalization in Northern Scandinavia and Finland. Acta Universitatis Upsaliensis, Studia Uralica Upsaliensia 31. Uppsala: Uppsala universitet.

Jensen, E. B. (2005). Skoleverket og de tre stammers møte. Tromsø: Eureka forlag.

Keskitalo, P., Määttä, K., \& Uusiautti, S. (2012). Sami education in Finland. Early Child Development and Care, 182(3-4), 329-343. http://dx.doi.org/10.1080/03004430.2011.646723

Knight, M. G., Bentley, C. C., Norton, N. E. L., \& Dixon, I. R. (2004). (De)Constructing (In)Visible Parent/Guardian Consent Forms: Negotiating Power, Reflexivity, and the Collective within Qualitative Research. Qualitative Inquiry, 10(3), 390-411. http://dx.doi.org/10.1177/1077800404263498

Kvale, S. (1996). Interviews: an introduction to qualitative research interviewing. Thousand Oaks, CA: Sage.

Lave, J., \& Wenger, E. (1991). Situated learning: legitimate peripheral participation. Cambridge: Cambridge University Press.

Lewis, M. P. (Ed.) (2009). Ethnologue: Languages of the World, (16th edition). Dallas, Tex.: SIL International.

Lund, K. (2006). The awareness of context in second language acquisition theories. In H. L. Andersen, K. Lund, $\&$ K. Risager (Eds.), Culture in language learning (pp. 57-86). Aarhus: Aarhus University Press.

Magga, O. H. (2002). Samisk språk - en oversikt. I Nordisk Ministerråd: Samiska i ett nytt årtusende (pp. 9-22). København: Nordiska Ministerrådet.

McLellan, E., McQueen, K., \& Neidig, J. (2003). Beyond the qualitative interview: Data preparation and transcription. Field Methods, 15(1), 63-84. http://dx.doi.org/10.1177/1525822X02239573

Minde, H. (2003). The Challenge of Indigenous: The Struggle for Sami Rights in Norway 1960-1990. In S. Jentoft, H. Minde, \& R. Nilsen (Eds.), Indigenous Peoples: Resource management and global rights (pp. 75-104). Delft: Eburon Publishers.

Minde, H. (2005). Assimilation of the Sami - implementation and consequences, gáldu čála. Journal of Indigenous Peoples Rights, 3, 1-34.

Niemi, E. (1997). Kulturmøte, etnisitet og statlig intervensjon på Nordkalotten. In R. B. Andersson (Ed.), Den nordiska mosaiken: språk- och kulturmöten i gammal tid och $i$ våra dagar: Humanistdagarna vid Uppsala universitet. Uppsala: Uppsala Universitet.

Nordic Sami Institute. (2005). Retreived October 14, 2012, from http://www.sami-statistics.info/english/default.asp?nc $=8506 \& \mathrm{id}=37$

Norton, B. (2001). Non-participation, imagined communities, and the language classroom. In M. Breen (Ed.), Learner contributions to language learning: New directions in research (pp. 159-171). London: Pearson Education.

Özerk, K. (2009). The revitalisation of a threathened indigenous language. The case of the Sami people in Norway. In P. A. Danaher, J. R. Leder, \& M. Kenny (Eds.), Traveller, nomadic and migrant education (pp. 132-144). New York: Routledge.

Patton, M. (1990). Qualitative evaluation and research methods. Beverly Hills, CA: Sage Publications.

Patton, M. Q. (2002). Qualitative research and evaluation method ( ${ }^{\text {rd }}$ ed.). London: Sage Publications.

Pettersen, T. (2007). Contemporary Sami demography-a "black hole" in research and policy making. In L. Elenius, \& C. Karlsson (Eds.), Cross-cultural communication and ethnic identities. Proceedings II from the conference Regional Northern Identity: from Past to Future at Petrozavodsk State University, Petrozavodsk 2006 (pp. 268-278). Luleå: Luleå tekniska universitet.

Skutnabb-Kangas, T. (2000). Linguistic genocide in education-or worldwide diversity and human rights? Mahwah, N.J.: Lawrence Erlbaum.

Solstad, K. J., Balto, A. M. V., Nygaard, V., Josefsen, E., \& Solstad, M. (2012). Samisk språkundersøkelse 2012. NF-rapport 7/2012. Bodø: Nordlandsforskning.

Solstad, K. J., Bongo, M., Eriksen, L., Germeten, S., Kramvig B., Lyngsnes, K., \& Nygaard, V. (2009). Samisk opplcering under LK06-samisk. NF-rapport 3/2009. Bodø: Nordlandsforskning.

Solstad, K. J., Bongo, M., Eriksen, L., Germeten, S., Lyngsnes, K., \& Solstad, M. (2010). Fra plan til praksis. Erfaringer med Kunnskapsløftet Samisk (LK06S), NF-rapport 6/2010. Bodø: Nordlandsforskning. 
Solstad, K. J., Nygaard, V., \& Solstad, M. (2012). Kunnskapsløftet 2006 Samisk - Mot en likeverdig skole? NF-rapport 1/2012. Bodø: Nordlandsforskning.

Todal, J. (1998). Minorities with a minority: Language and the school of the Sami areas of Norway. Language, Culture and Curriculum, 11(3), 354-366. http://dx.doi.org/10.1080/07908319808666562

Todal, Jon. (2011). Alvorleg nedgang for faget samisk som andrespråk. I Sámi allaskuvla: Samiske tall forteller 4. Kommentert samisk statistikk 2011. Rapport 1/2011. Guovdageaidnu: Sámi allaskuvla.

Utdanningsdirektoratet. (2006). Sami curriculum (LK06). Oslo: Utdanningsdirektoratet. Retrieved September 27, 2012, from http://www.udir.no/Stottemeny/English/Curriculum-in-English/_english/Sami-Curriculum/

Vygotsky, L. (2000). Thought and language. Cambridge, MA: MIT Press.

Vygotsky, L. S. (1978). Mind in society: The development of higher psychological processes. Cambridge, MA: Harvard University Press.

Wenger, E. (1998). Communities of practice: learning, meaning, and identity. Cambridge: Cambridge University Press.

Yancey, A. K., Ortega, A. N., \& Kumanyika, S. K. (2006). Effective recruitment and retention of minority research participants. Annual Review Public Health, 27, 1-28, http://dx.doi.org/10.1146/annurev.publhealth.27.021405.102113 